\title{
The research on software project schedule prediction and controlling
}

\author{
Boru $\mathrm{Xu}^{1, \mathrm{a}}$, Aihua Ren ${ }^{1, \mathrm{~b}}$, Sidou Dong ${ }^{1, \mathrm{c}}$ and Xin Wang ${ }^{1, \mathrm{~d}}$ \\ ${ }^{1}$ School of Beihang University, Beijing 510000, China; \\ aboruxu@qq.com, ${ }^{\text {brenah@buaa.edu.cn, }{ }^{c} \text { dongsidou@sina.com, }{ }^{d} 781594958 @ q q . c o m}$
}

Keywords: Project schedule management, project schedule control, schedule factor, AHP, Monte Carlo simulation.

\begin{abstract}
The control of software project schedule has been the emphasis and difficulty of software project management. Many software companies are focus on qualitative predicting and controlling of project schedule. Lacking of quantitative prediction of project schedule, it is difficult to quantitatively manage project schedule effectively. The paper proposes solutions for the problems of quantitatively predicting and controlling project schedule, and mines controllable factors that affect the schedule in each phase of project. The paper uses AHP method to select the key Schedule Factors, and establishes the relationship between the key Schedule Factors and the schedule variance. Finally, the paper combines Monte Carlo simulation method with software Process Performance Model, which is built by those key Schedule Factors, to create project schedule variance forecasting model. The paper adjusts the Schedule Factors in the predicting model to achieve the controlling of project schedule.
\end{abstract}

\section{Introduction}

The control of software project schedule has been the key and difficulty of the software project management. with the increasing of software products' scale and complexity, delay in the delivery of software products are increasingly common phenomenon. when the schedule deviation appears, if we only take appropriate remedial measures, and ignore the prediction of deviation on project schedule, it would be difficult to achieve effective project schedule management.

The paper researches how to achieve the project's schedule forecasting and monitoring by building forecasting model of the project schedule variance. The key point is to effectively summarize the Schedule Factors of each phase of the project and use these factors to build relationship with the schedule variance. Many factors affect the project schedule, some of which are adjustable, while others are not. Only to find Schedule Factors, which can be regulated, and establish association between them and the schedule variance, can effective forecasting and monitoring of the schedule variance be achieved. If the forecasting results deviate from the target, we should adjust the corresponding Schedule Factors, then the project schedule variance can fall within reasonable limits.

Due to limited available resources of project, we needs to consider a variety of conditions to select Schedule Factors which have greater impact on the project schedule than others. The paper develops a mechanism that can simulate real process of uncertainty to arrive at results that are closest to reality based on existing models. The paper utilizes analytic hierarchy process (AHP) to select Schedule Factors and uses Monte Carlo simulation method to build forecasting model of the project schedule variance.

\section{Determining the project Schedule Factors}

The paper aims to research the software project of waterfall model and collects 30 factors which will affect the project schedule (hereinafter referred to as Schedule Factor).

The AHP method is used to select the project Schedule Factors in each phase of the software project. How to use AHP method please reference references [3] and references [4]. Here take the 
selection of Schedule Factors in design phase as an example for utilizing AHP satisfy references [3] and references [4].

Then use the AHP method to select the remaining Schedule Factors of other phases. Finally, the paper obtains 10 Schedule Factors as is shown in Table 1.

Table 1 The selected Schedule Factors using AHP method

\begin{tabular}{|c|c|c|}
\hline ID & SCHEDULE FACTOR NAME & $\begin{array}{c}\text { CLASSIFIC } \\
\text { ATION }\end{array}$ \\
\hline 1 & Team Size & P \\
\hline 2 & Customer business skills & $\mathrm{P}$ \\
\hline 3 & Design staff skills & $\mathrm{D}$ \\
\hline 4 & Coding staff skills & $\mathrm{D}$ \\
\hline 5 & The number of requirements change in designed phase & $\mathrm{C}$ \\
\hline 6 & The rate of personnel change in the Coding phase & $\mathrm{C}$ \\
\hline 7 & The number of requirements change in Coding phase & $\mathrm{C}$ \\
\hline 8 & The number of integration testing Bug & $\mathrm{T}$ \\
\hline 9 & The number of requirements change in testing phase & $\mathrm{T}$ \\
\hline 10 & & \\
\hline
\end{tabular}

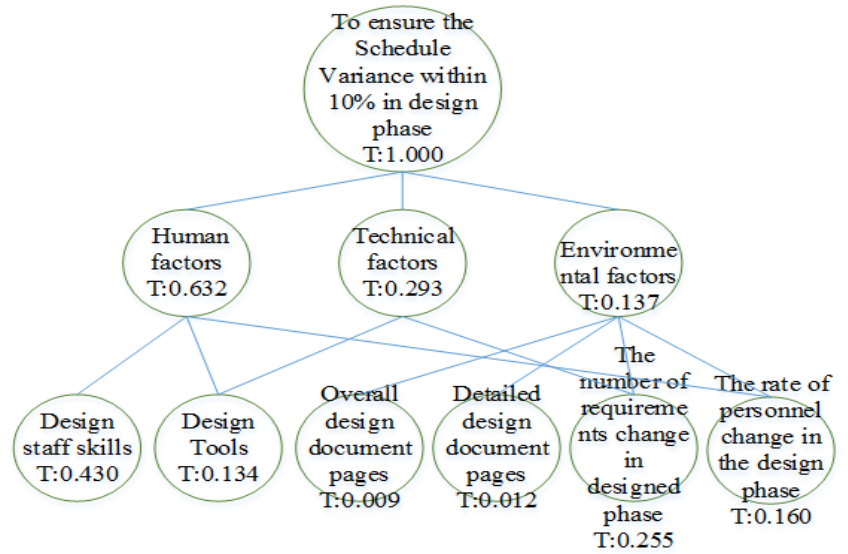

Fig. 1 The selection result of the Schedule Factors in design phase

\section{Build Project Schedule Variance Forecasting Model}

The paper combined schedule related models with Monte Carlo simulation method to build the project schedule variance prediction model. Here take an example to explain how to build the project schedule variance prediction model of coding phase, the data shown in table 3 comes from a company. Specific steps are as follows. 
Table 2 historical data of a software company

\begin{tabular}{|c|c|c|c|c|c|c|c|c|c|c|c|}
\hline ID & f01 & f11 & f12 & f21 & f22 & f31 & f32 & f33 & PWED & SD3 & SD3' \\
\hline 1 & 5 & 3 & 2 & 6 & 1 & 3 & 0 & 2 & 120 & 8 & 0.067 \\
\hline 2 & 3 & 5 & 3 & 7 & 2 & 3 & 0 & 1 & 60 & 1.5 & 0.025 \\
\hline 3 & 3 & 9 & 4 & 5 & 2 & 4 & 0.333 & 2 & 40 & -1.5 & -0.038 \\
\hline 4 & 4 & 4 & 6 & 8 & 2 & 4 & 0 & 2 & 120 & 5 & 0.042 \\
\hline 5 & 4 & 5 & 3 & 9 & 6 & 9 & 0 & 2 & 120 & 8 & 0.067 \\
\hline 6 & 7 & 4 & 4 & 5 & 4 & 5 & 0.143 & 3 & 150 & 16 & 0.107 \\
\hline 7 & 5 & 5 & 8 & 4 & 3 & 5 & 0 & 2 & 120 & 5.5 & 0.046 \\
\hline 8 & 5 & 4 & 4 & 7 & 4 & 7 & 0 & 4 & 240 & 14.5 & 0.060 \\
\hline 9 & 5 & 5 & 5 & 8 & 3 & 5 & 0 & 3 & 180 & 10 & 0.056 \\
\hline 10 & 1 & 3 & 3 & 4 & 4 & 5 & 0 & 1 & 30 & 3 & 0.1 \\
\hline 11 & 8 & 6 & 5 & 7 & 8 & 9 & 0.25 & 5 & 360 & 24.5 & 0.068 \\
\hline 12 & 6 & 6 & 5 & 5 & 4 & 6 & 0.333 & 3 & 150 & 11 & 0.073 \\
\hline 13 & 6 & 7 & 6 & 5 & 3 & 7 & 0 & 3 & 120 & 7 & 0.058 \\
\hline 14 & 7 & 7 & 7 & 7 & 5 & 7 & 0.143 & 4 & 150 & 14 & 0.093 \\
\hline 15 & 4 & 8 & 6 & 9 & 5 & 5 & 0 & 4 & 240 & 11 & 0.046 \\
\hline 16 & 7 & 6 & 5 & 6 & 3 & 8 & 0 & 5 & 180 & 15 & 0.084 \\
\hline 17 & 5 & 8 & 7 & 6 & 6 & 4 & 0.20 & 4 & 150 & 14 & 0.093 \\
\hline 18 & 8 & 9 & 7 & 5 & 6 & 9 & 0 & 4 & 180 & 14 & 0.078 \\
\hline 19 & 9 & 9 & 8 & 8 & 2 & 6 & 0.222 & 3 & 240 & 7 & 0.030 \\
\hline 20 & 10 & 8 & 6 & 8 & 3 & 9 & 0.111 & 2 & 360 & 7 & 0.019 \\
\hline
\end{tabular}

\begin{tabular}{|c|c|c|c|}
\hline $\begin{array}{l}\text { P0: Project } \\
\text { plaming phase }\end{array}$ & $\begin{array}{l}\text { Pl: Requirements } \\
\text { a malys sis phase }\end{array}$ & P2: Design phase & P3: Coding phase \\
\hline F01: Team Size & $\begin{array}{l}\text { F11: Requirements } \\
\text { analysts skills } \\
\text { F12: Customer business } \\
\text { skills }\end{array}$ & $\begin{array}{l}\text { F21: Design staff skills } \\
\text { F22: The number of } \\
\text { requirements change in } \\
\text { designed phase }\end{array}$ & $\begin{array}{l}\text { F31: Coding staff skills } \\
\text { F32:The rate of personnel change } \\
\text { in the Coding phase } \\
\text { F33: The number of requirements } \\
\text { change in testing phase }\end{array}$ \\
\hline
\end{tabular}

Fig. 2 Symbol description of the project phases and Schedule Factors

1) Mark Each phase as Pi (subscript i represents the software project phase No., $i=0,1,2,3$ ) and each Schedule Factor as Fij (subscript i represents project phase No., $m=0,1,2,3$. subscript $j$ represents Schedule Factor No.), symbol description of the project phases and Schedule Factors are shown in Fig. 3. Since the paper is building the project schedule variance forecasting model of coding phase, the Schedule Factors of testing phase are ignored.

2) Build process performance models between the project schedule variance of coding phase and the Schedule Factors (list in Table 1) using history data (list in Table 2). The paper uses mathematical statistics build a multiple linear regression model as shown in Eq. 1. The Equation indicates that: "project schedule variance of coding phase" is proportional to "Team Size", "The number of requirements change in designed phase"," The rate of personnel change in coding phase" ,and is inversely proportional to "Customer business skills"," Requirements analysts skills”," Design staff skills” and" Coding staff skills”. Divide Eq. 1 by the planned effective working days (short for PWED) at the end of coding phase, and get a percentage of schedule variance, as is shown in Eq. 2. The factors, "Design staff skills" and "The rate of personnel change in the Coding phase”, have been removed during establishment process of the forecasting model.

$$
\begin{aligned}
& \mathrm{SD} 3=1.5 * \mathrm{~F} 01-1.2 * \mathrm{~F} 11-0.4 * \mathrm{~F} 12+1.8 * \mathrm{~F} 22-0.8 * \mathrm{~F} 31+2.9 * \mathrm{~F} 33 \\
& \mathrm{SD}{ }^{\prime}=(1.5 * \mathrm{~F} 01-1.2 * \mathrm{~F} 11-0.4 * \mathrm{~F} 12+1.8 * \mathrm{~F} 22-0.8 * \mathrm{~F} 31+2.9 * \mathrm{~F} 33) / \mathrm{PEWD}
\end{aligned}
$$

3) The paper uses mathematical statistics to build probability distribution of each Schedule Factors. The result is shown in Table 3. 
Table 3 probability distribution of Schedule Factors

\begin{tabular}{|c|c|c|}
\hline $\begin{array}{c}\text { Schedule } \\
\text { Factor }\end{array}$ & $\begin{array}{c}\text { probability } \\
\text { distribution }\end{array}$ & Parameters \\
\hline F01 & $\begin{array}{c}\text { Triangular } \\
\text { distribution }\end{array}$ & $\begin{array}{c}\text { lower limit: } 1 \\
\text { upper limit: } 10 \\
\text { mode: 5 }\end{array}$ \\
\hline F11 & $\begin{array}{c}\text { Uniform } \\
\text { distribution }\end{array}$ & $\begin{array}{c}\text { lower limit: 3 } \\
\text { upper limit: 9 }\end{array}$ \\
\hline F12 & $\begin{array}{c}\text { Uniform } \\
\text { distribution }\end{array}$ & $\begin{array}{c}\text { lower limit: 2 } \\
\text { upper limit: 8 }\end{array}$ \\
\hline F22 & $\begin{array}{c}\text { Triangular } \\
\text { distribution }\end{array}$ & $\begin{array}{c}\text { lower limit: 0 } \\
\text { upper limit: } 8 \\
\text { mode: 3 }\end{array}$ \\
\hline F31 & $\begin{array}{c}\text { Uniform } \\
\text { distribution }\end{array}$ & $\begin{array}{l}\text { lower limit: 3 } \\
\text { upper limit: 9 }\end{array}$ \\
\hline F33 & Triangular & $\begin{array}{l}\text { lower limit: 0 } \\
\text { upper limit: 5 } \\
\text { distribution }\end{array}$ \\
\hline
\end{tabular}

4) Assume that the current project phase is design phase, collect data shown in Table 4 by using the form, then determinate data not collected by combining Eq. 2, and get Table 5. In addition, the PWED value of the project is 126 days.

Table 4 Value which has been determined Schedule Factors

\begin{tabular}{|c|c|}
\hline Schedule Factor & Value \\
\hline F01 & 6 \\
\hline F11 & 7 \\
\hline F12 & 6 \\
\hline F22 & 2 \\
\hline
\end{tabular}

Table 5 Value which has not been determined Schedule Factors

\begin{tabular}{|c|c|c|}
\hline $\begin{array}{c}\text { Schedule } \\
\text { Factor }\end{array}$ & $\begin{array}{c}\text { Probability } \\
\text { distribution }\end{array}$ & Remark \\
\hline F31 & $\begin{array}{c}\text { Uniform } \\
\text { distribution }\end{array}$ & $\begin{array}{c}\text { lower limit: } 3 \\
\text { upper limit: } 9\end{array}$ \\
\hline F33 & $\begin{array}{c}\text { Triangular } \\
\text { distribution }\end{array}$ & $\begin{array}{c}\text { lower limit: } 0 \\
\text { upper limit: } 5 \\
\text { mode: } 2\end{array}$ \\
\hline
\end{tabular}

5) Take Eq. 2, data listed in Table 4 and Table 5, the PWED value as the input of Monte Carlo simulation, as is shown in Fig. 3.

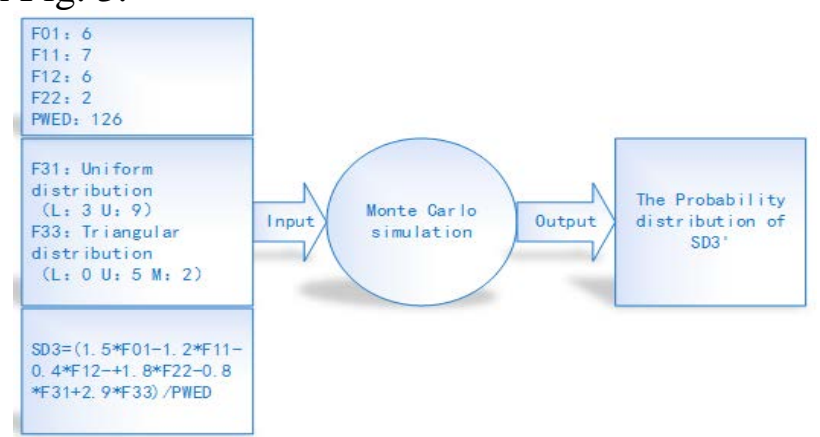

Fig. 1 schedule variance forecasting model of coding phase

6) Use Crystalball software developed by Oracle to conduct Monte Carlo simulation. First, define Schedule Factors F31 and F32 as assumptions, SD3' as forecast. Second, set the number of experiments to 1000 . Third, start the simulation. The result is the probability distribution of the schedule variance percentage of coding phase as is shown in Fig.4. As can be seen from the figure, there are $95.60 \%$ confidence to ensure that the schedule variance percentage of coding phase will fall in $-2.0 \%$ to $8.0 \%$. 


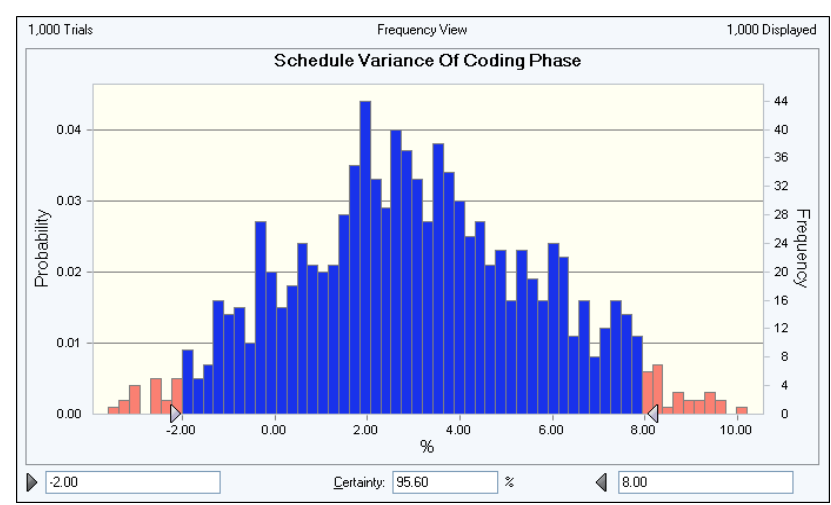

Fig. 2 Schedule variance forecasting result of coding phase

7) The project is implemented as planned, and didn't take any improvement. At the end of coding phase, the project carry out 126 days, the actual schedule is 5 days lag behind the planned schedule. Converted to the percentage, it is $4 \%$, which falls $-2 \%$ to $8 \%$. That indicates the forecasting model is valid.

\section{Control the Project Schedule Variance}

The method of controlling the project schedule variance is mainly to adjust the Schedule Factors of subsequent phases. Assume that the current is Design phase, the paper takes some adjustments.

The probability distribution before adjustment,

F31:Uniform distribution, Lower limit:3,Upper limit: 9

F32:Triangular distribution, Lower limit: 0,Upper limit: 5,Mode: 2.

The probability distribution after adjustment,

F31:Uniform distribution, Lower limit:6 ,Upper limit: 9

F32:Triangular distribution:Lower limit: 0 ,Upper limit: 3,Mode: 2

We can train the developer before coding or select coding staff with high capability to improve F31 and conduct requirements confirm at the end of the design phase to improve F32.

As is shown in Fig.5, there are 95.5\% confidence to ensure that the schedule variance percentage of coding phase will falls in $-3.0 \%$ to3.0\%

As can be seen from the effect of the adjustment, by improving the Coding staff skills or reducing the number of requirements change in Coding phase, can the schedule variance percentage of Coding phase be decreased, and the latter's adjustment effect is better than the former's.

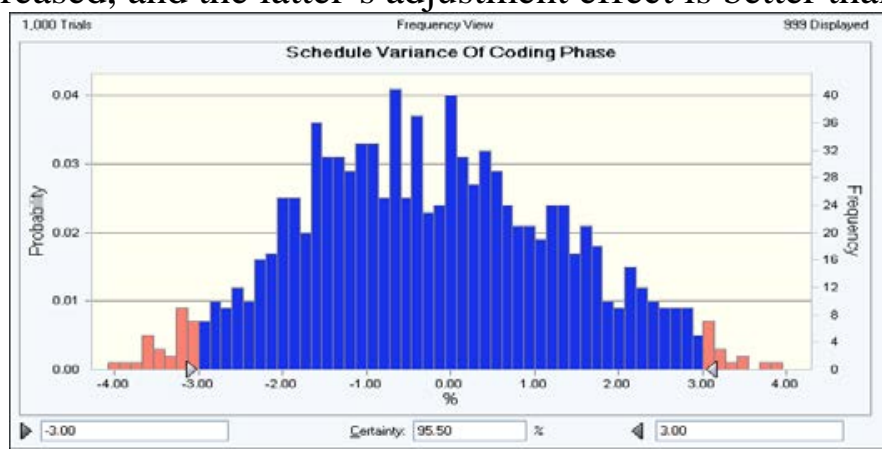

Fig.5 Schedule variance forecasting result of coding phase after adjust F31 and F32

\section{Conclusion and Future Work}

The paper selects 30 Schedule Factors from 5 phases of software project. These Schedule Factors are mapped into corresponding phases. The AHP method is used to select Schedule Factors which have more influence on the schedule variance than others, the paper finally selects 8 Schedule Factors. By analyzing the real software project data from a company, the paper builds a multiple linear regression model between the schedule variance of coding phase and 6 Schedule Factors which are among the 8 previously selected Schedule Factors. Then the paper combines the 
model with Monte Carlo simulation to build a project schedule variance forecasting model of coding phase. Furtherly a real project schedule variance of coding phase is predicted successfully. At the same time, the paper takes some adjustment to the Schedule Factors of the model, and reduces the schedule variance of coding phase effectively. Based on the schedule forecasting model, the author of the paper is developing a practical software schedule forecasting tool. We hope the model and the tool can help software companies achieve a successful project schedule management.

\section{References}

[1] CMMI Product Team. Capability Maturity Model Integration (CMMI), CMMI for Development, Version 1.3[S]. Software Engineering Institute, Carnegie Mellon University, 2010.

[2] Project Management Institute. A Guide to the Project Management Body of Knowledge: PMBOK® Guide[C]. Project Management Institute, 2008.

[3] Xiaofen Luo, Aihua Ren, Meng Li. The application of AHP and SPC techniques in quantitative process management[J]. Computer Engineering and Design, 2010 (012): 2749-2753.

[4] Peng Y, Kou G, Wang G, et al. Ensemble of software defect predictors: an AHP-based evaluation method[J]. International Journal of Information Technology \& Decision Making, 2011, 10(01): 187-206.

[5] McLeish D L. Monte Carlo simulation and finance[M]. Wiley. com, 2011.

[6] Xili Chen, Yanlin Zhang, Xinsheng Cui. The application of Monte Carlo Simulation in Project Management[J]. Industrial Engineering, 2004, 7(3): 51-55.

[7] Oracle. CrystalBall User Manual7.3 [S]. Oracle, 2007. 